\title{
SOME FRACTIONAL DIFFERENTIAL INEQUALITIES AND THEIR APPLICATIONS
}

\author{
K. M. FuRATI AND N.-E. TATAR
}

Abstract. We consider some inequalities involving derivatives of non-integer order. These inequalities arise naturally when investigating differential equations of fractional order. We find some bounds for solutions of these inequalities and give some applications.

Mathematics subject classification (2000): 26A33, 15A39, 26D07, 26D10, 34A40.

Key words and phrases: Bihari-Gronwall inequality, differential inequalities, fractional differential inequalities, integral inequalities, Riemann-Liouville fractional integral, summable fractional derivative.

\section{REFERENCES}

[1] D. BAINOv, P. SimeOnov, Integral Inequalities and Applications, volume 57, Kluwer Acad. Publishers, Dordrecht, Boston, London, 1992.

[2] M. KIRANE, N.-E. TATAR, Global existence and stability for some semilinear problems, Archivum Mathematicum, 36, (2000), 33-44.

[3] M. W. MiChaLSKI, Derivatives of noninteger order and their applications, Dissertationes Mathematicae, 328, (47) (1993).

[4] B. G. PACHPATTE, Inequalities for Differential and Integral Equations, volume 197 of Mathematics in Science and Engineering, Acad. Press, San Diego-London, 1998. Edited by W. F. Ames.

[5] S. G. SAmko, A. A. KILBAS, AND O. I. Marichev, Fractional Integrals and Derivatives, Theory and Applications, Gordon and Breach, Amsterdam, 1993. Engl. Trans. From the Russian 1987. 